\title{
Products Selection Modeling of Medicine Manufacturing Industry Development in Beibuwan Economical Zone
}

\author{
ZENG Jian-hong \\ Guangxi Economic Management Cadre College Nanning China
}

\begin{abstract}
Beibuwan Economical Zone of Guangxi Province has the necessary basis and conditions to develop the madicine manufacturing industry.It is significant to select products which ficilitate the development of madicine manufacturing industry from the prospective of promoting the development of the industry smoothly. The feature of selection of essential products of medicine manufacturing can be summarized as multiobjectiveness, multi-layer, fuzziness and the interaction and penetration of different objectives. Due to these characteristics, analysis is made through analytic hierarchy process (AHP) by this thesis. The paper put forward the developmental sequence of madicine manufacturing industry in Beibuwan Economical Zone of Guangxi Province by adopting analytic hierarchy process, and pointed out that, among others, the technical competence is the most influnctial factor of a company. The appropriate developmental sequence of the products selected is biological and biochemical products, medicinal chemicals, chemical medicine and preparations. This research is in favor of speeding up the development of competitive products and creating industry competition.
\end{abstract}

Index Terms: Beibuwan Economical Zone;Medicine Manufacturing Industry;Products,select

(C) 2012 Published by MECS Publisher. Selection and/or peer review under responsibility of the Research Association of Modern Education and Computer Science

\section{Introduction}

The pharmaceutical industries in Guangxi Beibu Gulf economic region mainly includes chemical medicine manufacturing, slices processing of Chinese crude drugs, Chinese patent drug manufacturing, bio-chemical medicine manufacturing, sanitary materials manufacturing and medicinal suppliers manufacturing, etc[1]. The major enterprises are Guangxi Nanning Chemical Pharmaceutical Co., Ltd., North Sea Guofa Halobios Industry Stock Limited Corporation, Nanning Sanjin Pharmaceutical Co. Ltd., Guangxi Madison Pharmaceutical Co. Ltd., Guangxi Bangqi Pharmaceutical Co., Ltd., etc.

Guangxi Nanning Chemical Pharmaceutical Co., Ltd. mainly produces sorbitol, mannitol, isomaltitol and compressible sugar. In the meanwhile, the key technological breakthrough of liquid glucose chemical isomerism producing mannitol \& industrialization application research is the New Product and New Technology Project of Autonomous Region lever in 2008[2].North Sea Guofa halobios industry Stock Limited Corporation is united by

Corresponding author:

E-mail address: 1462919932@qq.com 
some enterprises in minority nationality regions like Guangxi, Tibet and Inner Mongolia, and be participated in shareholding and cooperated with colleges, universities and institutions such as Tsinghua University, Oceanographic Institution of Chinese Academy of Sciences and Planning and Design Institute of Ministry of Agriculture, which is domestic only listed company engaged in the overall development and processing of halobios resources. To develop some green products with resource characteristics and meeting the needs of domestic and foreign markets, such as pearl jewelry, cosmetics, pharmaceuticals, oligosaccharide marine biogenic pesticides and seaweed biological liquid fertilizers, etc. The main products are Sulfacetamide Sodium Eye Drops, Bolus of Six Drugs Including Rehmannia, Lycium-rehmannia Pills, Bolus of Ten Powerful Tonics, Pearl Powder, Xiangsha Liujun pills, Gastralgia Tablet and Haematinic and Sedative Tablets.Nanning Sanjin Pharmaceutical Co. Ltd. is the subsidiary of Guilin Sanjin Group Stock Limited Corporation, which is a pharmaceutical company mainly producing Chinese patent drug preparation. The main preparation of the company is medicinal capsule. The company invests 10 million Yuan to construct the factory district and factory buildings according to GMP standards, introducing into various advanced production and testing equipments and devices, and passed GMP scene certification in August 2004. The main kind is dracaena capsule, and the annual producing capacity is 150 million pieces. The dracaena capsule produced by the company is National Chinese Drugs Protected Variety, has the name of "best medicine for invigorating blood circulation", which is in the "National Essential Drug List" and "National Basic Medical Insurance and Industrial Injury Insurance Directory of Drugs".In the authorizing production range of Guangxi Madison Pharmaceutical Co. Ltd, there are tablets, capsules, tinctures, oral liquids and chemical material drugs. The productions are Coenzyme Q10 Material Drugs, Coenzyme Q10 Capsules, Refreshment Tinctures and Healthy after Operation Oral Liquids. In addition, the company owns national key technical innovation project which has been approved to determine and construct, international natural anti-cancer drug, the advanced "curative effect HCPT (hydroxycamptothecine)" treatment infusion solution[3].

\section{The Selection Principles and Methods of the Key Productions in Pharmaceutical Manufacturing in Guangxi Beibu Gulf Economic Region}

\subsection{The principles of promoting the development of pharmaceutical manufacturing}

1) The purpose of choosing some products in pharmaceutical manufacturing as key products to establish technique supporting industry development is to force the industrial structure adjustment of pharmaceutical manufacturing and the forming development of pharmaceutical manufacturing industry cluster through the technical innovation of the products and the extension of industry chain, and to achieve the development of pharmaceutical manufacturing industry[4].

2) The principles of forming new growth points.

The high-tech products of pharmaceutical manufacturing are with high technology contents, strong market competitiveness and development prospects, are the base of the forerunner industries development in Beibu Gulf Economic Region. While the forerunner industries lead the direction of the national economic future development in Beibu Gulf region, which represent the direction of technique development and industrial structure evolution. Ultimately forming new economical growth points, and having a holistic and long-term effect on the economic development of the region.

3) The principles of in line with actual economic condition in Beibu Gulf and producing products with great market potential.

The product value can only be achieved by market, and the benefit can only be created by market as well. So the selected key products of pharmaceutical manufacturing should have favorable market prospects. In addition, though the Beibu Gulf Economic Region develops rapidly, the technological lever still fall behind in some relatively developed region, the key product selection process of pharmaceutical manufacturing should pay full attention to this reality.

4) The principles of forming regional characteristics and comparative advantages.

The characteristics and advantages are the important prerequisite and basis in promoting sound development of the economy in Beibu Gulf Economic Region. Developing pharmaceutical manufacturing industry with the 
support of technology is an important way to promote industry upgrade and industry optimization of pharmaceutical manufacturing. There are rich animal, plant, marine and other resources in Beibu Gulf, so the key products selection of pharmaceutical manufacturing should make full use of this comparative advantage, and adding technology elements, to make sustainable development in this industry.

\subsection{Selection Method of Essential Products of Medicine Manufacturing in Guangxi Beibu Gulf Economic Zone}

The feature of selection of essential products of medicine manufacturing can be summarized as multiobjectiveness, multi-layer, fuzziness and the interaction and penetration of different objectives. Due to these characteristics, analysis is made through analytic hierarchy process (AHP) by this thesis. This method was raised by the operational research expert Professor Saaty in University of Pittsburgh in early 1970s. It is a decision analyzing method for hierarchical weighting, making use of network system theory and multi-objective comprehensive evaluation. Based on the specific analysis of the nature, influential variables and internal relationship of complicated decisive issues, AHP mathematicizes thinking process through a small number of quantitative information to provide a simple decision method for complicated decision issues with multiple objects, principles and no structural features. It is designed for the case in which the decision results cannot be precisely measured. Taking these elements into consideration, AHP can basically satisfy the needs brought by the multi-objectiveness, multi-layer and fuzziness of selection and evaluation of essential products in medicine manufacturing.

The principle of AHP is to break the complicated issue down into several components and use these components to form a hierarchical structure according to dominative relationship. The importance of each element is judged by comparison, which together with the judgment of comprehensive decision maker, are used to rank the decision solution[5].

The first step is to build a construction model after the systematic problem is summarized and layered. In this model, complicated issues are divided into several components, which is called element. Then these elements are categorized into different hierarchies. The elements in the same hierarchy act as rules and dominate the elements of lower one, while at the same time; they are subordinated to higher ones.

The structure built on the basis of the dominating relationship between higher and lower elements is called hierarchical structure. The higher elements can control all or some of the lower ones. The number of layer in this structure is influenced by or independent of the complexity of the issue and the analyzing layer. The elements dominated by one element should not exceed nine. Otherwise, it will cause undesired difficulties to comparison.

In a hierarchical structure, the higher element $\mathrm{C}$ is assumed as a rule and its dominating lower elements are U1, $\mathrm{U} 2 \ldots$... Fn. For rule $\mathrm{C}$, the relative importance is called weighting. It can be divided into two cases. If the importance of $\mathrm{U} 1, \mathrm{U} 2 \ldots \mathrm{Un}$ for $\mathrm{C}$ can be measured through quantity, then the weighting can be decided directly. If it can only be measured by quality, the comparison is preferred, i.e. for $\mathrm{Ui}$ and $\mathrm{Uj}$, which is more important for rule $C$ and how important it is. In general, a value is designed to the importance by using 1 9.

For rule $\mathrm{C}$, a comparison matric is obtained by comparing the importance among $\mathrm{n}$ elements.

$$
A \square\left(a_{i j}\right)_{n \times n}
$$

Which is the element and the importance of relative proportion of $\mathrm{C}$ scale

Given $\mathrm{n}$ elements $\mathrm{u} 1, \mathrm{u} 2, \ldots$, un for criteria $\mathrm{C}$ to judge matrix A, find $\mathrm{u} 1, \mathrm{u} 2, \ldots$, un to the relative weights of criteria $\mathrm{C}$, shall be written in vector form.

Will determine the n-matrix A row vector of normalized arithmetic mean, similar to a weight vector, that is,

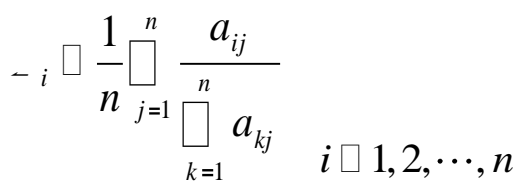

There are similar columns and the normalization method, that is 


$$
-_{i} \square \frac{\square_{j=1}^{n} a_{i j}}{n \square_{k=1}^{n} \square_{j=1}^{n} a_{k j}} \quad i \square 1,2, \cdots, n
$$

Single criterion in the calculation of the weight vector, must also be consistency test

Consistency index calculation C.I.(consistency index)

$$
\text { C.I. } \square \frac{\ell_{\max } \square n}{n \square 1} .
$$

Find the corresponding average random consistency index R.I.(random index).

Table 1 shows the order of 1 to 15 Reciprocal Matrix 1000 by the average random consistency index.

TABLE 1. AVERAGE RANDOM CONSISTENCY INDEX R.I.

\begin{tabular}{c|c|c|c|c|c|c|c|c}
\hline $\begin{array}{l}\text { Matrix } \\
\text { order }\end{array}$ & 1 & 2 & 3 & 4 & 5 & 6 & 7 & 8 \\
\hline R.I & 0 & 0 & 0.52 & 0.89 & 1.12 & 1.26 & 1.36 & 1.41 \\
\hline $\begin{array}{l}\text { Matrix } \\
\text { order }\end{array}$ & 9 & 10 & 11 & 12 & 13 & 14 & 15 & \\
\hline R.I. & 1.46 & 1.49 & 1.52 & 1.54 & 1.56 & 1.58 & 1.59 & \\
\hline
\end{tabular}

Consistency ratio calculated C.R.(consistency ratio)

$$
\text { C.R. } \square \frac{\text { C.I. }}{\text { R.I. }}
$$

When $\mathrm{CR}<0.1$, the matrix to determine the consistency that is acceptable; when the $\mathrm{CR} \geq 0.1$, it should make the appropriate amendments to the comparison matrix.

Layers of elements on the target layer calculated the total order weight. Important top-down sort of total power under the weight of a single criterion were synthesized, and layer by layer to determine the overall consistency test.

\section{The Selection MODELING of Main Products of Pharmaceutical Industry of Guangxi Beibu Gulf Economic Zone}

\section{1 The establishment of a hierarchical structure model}

In view of current situation of Pharmaceutical Industry in Guangxi Beibu Gulf, the main products of this industry include: the original drugs of chemicals, the preparation of chemicals, the decoction pieces of Chinese material medical, traditional Chinese medicine patent prescription, veterinary drugs, biologic and biochemical products, sanitary material and medical appliance etc. The structural model of Pharmaceutical Industry can be indicated as figure1. 


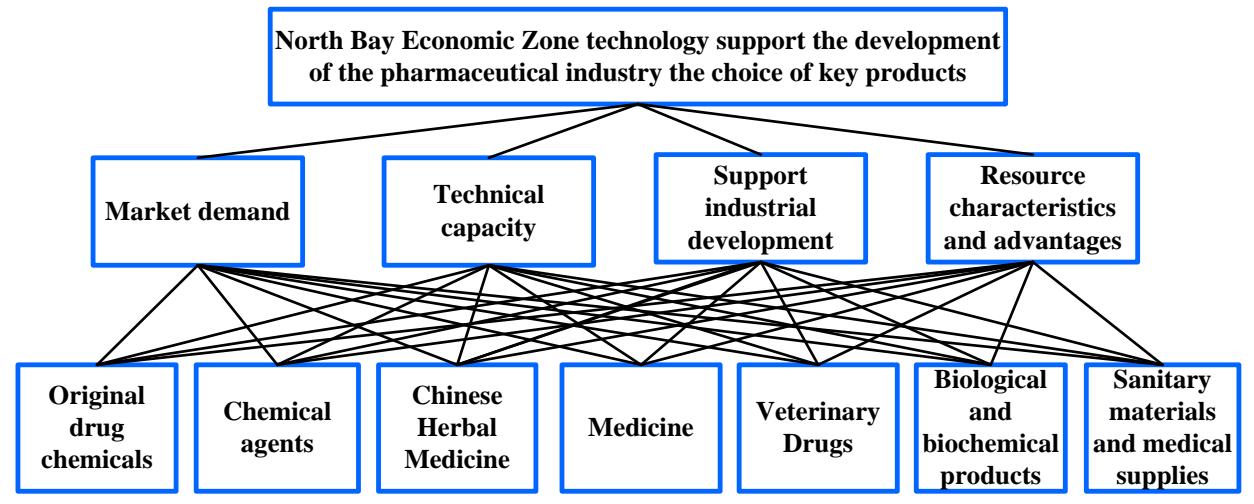

Fig 1: AHP hierarchical structure model of main products of Pharmaceutical Industry of Guangxi Beibu Gulf Economic Zone

\section{2 From the matrix structure relation of the target-layer, middle-layer, and scheme-layer, we could generate their weights respectively, then, we could rank them accordingly by their weights in Pharmaceutical Industry.}

1) the weight and ranking of middle-layer in target-layer .

We can obtain, from model calculation, the technical capacity is most important. We should first consider it when we are selecting main products, whose weight coefficient is high to 0.4131 . Second, we should take the advantageous factor caused by market requirement into consideration, whose weight coefficient is 0.2769 . Then we should think over the advantageous factor of characteristic resources to products, whose weight coefficient is 0.1856. Last, we should take the supporting capacity of the products to the whole industry into account, whose weight coefficient is 0.1244 . (Table 2 ).

TABLE 2 .LAYER IN THE MIDDLE LAYER IN THE TARGET WEIGHT AND SORTING

\begin{tabular}{|c|c|c|c|c|c|c|}
\hline $\begin{array}{l}\text { North Bay Economic Zone technology } \\
\text { support the development of the } \\
\text { pharmaceutical industry the choice of } \\
\text { key products }\end{array}$ & $\begin{array}{l}\text { Techni } \\
\text { cal } \\
\text { capacit } \\
\text { y }\end{array}$ & $\begin{array}{c}\text { Support } \\
\text { industrial } \\
\text { development }\end{array}$ & $\begin{array}{l}\text { Market } \\
\text { demand }\end{array}$ & $\begin{array}{c}\text { Resource } \\
\text { characteristics } \\
\text { and } \\
\text { advantages }\end{array}$ & Weight & sort \\
\hline Technical capacity & 1.0000 & 3.3201 & 1.4918 & 2.2255 & 0.4131 & 1 \\
\hline Support industrial development & 0.3012 & 1.0000 & 0.4493 & 0.6703 & 0.1244 & 4 \\
\hline Market demand & 0.6703 & 2.2255 & 1.0000 & 1.4918 & 0.2769 & 2 \\
\hline $\begin{array}{c}\text { Resource characteristics and } \\
\text { advantages }\end{array}$ & 0.4493 & 1.4918 & 0.6703 & 1.0000 & 0.1856 & 3 \\
\hline
\end{tabular}

2)the weight and ranking of decision -layer in the whole target-layer.

We could draw a conclusion by the overall ranking of major products of decision-layer in the target-layer that we should first consider the biologic and biochemical products, whose weight coefficient is 0.2773 , than 
consider the original drugs of chemicals, whose weight coefficient is 0.1503 . The preparation of chemicals ranks the third with a weight coefficient of 0.1498 . (Table 3).

TABLE 3 .DECISIOM-MAKING LAYER IN THE OVERALL GOAL OF THE WEIGHT AND SORTING

\begin{tabular}{ccccccc}
\hline $\begin{array}{c}\text { North Bay Economic Zone technology } \\
\text { support the development of the } \\
\text { pharmaceutical industry the choice of } \\
\text { key products }\end{array}$ & $\begin{array}{c}\text { Technical } \\
\text { capacity } \\
0.4131\end{array}$ & $\begin{array}{c}\text { Support } \\
\text { industrial } \\
\text { development } \\
0.1244\end{array}$ & $\begin{array}{c}\text { Market } \\
\text { demand } \\
0.2769\end{array}$ & $\begin{array}{c}\text { Resource } \\
\text { characteristics } \\
\text { and } \\
\text { advantages } \\
0.1856\end{array}$ & weight sort \\
\hline $\begin{array}{c}\text { Chemical agents } \\
\text { Medicine }\end{array}$ & 0.1530 & 0.1522 & 0.1557 & 0.1324 & 0.1498 & 3 \\
Veterinary Drugs & 0.0816 & 0.1246 & 0.1275 & 0.1975 & 0.1212 & 4 \\
$\begin{array}{c}\text { Original drug chemicals } \\
\text { Chinese Herbal Medicine }\end{array}$ & 0.1253 & 0.0665 & 0.0700 & 0.0995 & 0.0978 & 7 \\
Biological and biochemical products & 0.1667 & 0.1859 & 0.1513 & 0.0887 & 0.1503 & 2 \\
Sanitary materials and medical & 0.0649 & 0.1020 & 0.1044 & 0.1617 & 0.0984 & 6 \\
supplies & 0.2868 & 0.0835 & 0.1074 & 0.0791 & 0.1051 & 5 \\
Test (CR) & 0.0226 & 0.0005 & 0.0347 & 0.0024 & & \\
\hline
\end{tabular}

From table 3 we could see that the weight of biologic and biochemical products is far higher than other categories in an integrated weight calculation. That is to say, biologic and biochemical product is the most important category in all the categories of main products of Pharmaceutical Industry in Guangxi Beibu Gulf Economic Zone. At the same time, we should pay attention to the development of sea-medicines during our great efforts in developing biologic and biochemical product due to an advantageous geographical position of Beibu Gulf Economic Zone which is close to the sea. To sum up, We should take full use of marine resources and build a research platform and numbers of key Laboratories of sea-medicines. By a concentration of scientific and technological strength, we could research collaborative to develop new products and form characteristic industry group of biologic and biochemical products, thus to supply a gap in domestic biologic and biochemical products area.

\section{Conclusion}

As mentioned above, it is significant to make use of the traditional industry base, resource advantage and the wealth of oceans in the progress of medicine manufacturing industry development in Beibuwan Economical Zone of Guangxi Province, to speed up the development of technological innovation and biological and biochemical products depended on scientific and technological improvement; It is significant to accelerate the development of new drugs and to develop medicinal chemicals, chemical medicine and preparations by using the traditional industry base; It is significant to influence the inland market of China as well as Asean market by utilizing the convenient logistics development of Beibuwan Economical Zone of Guangxi Province, and finally make the medicine manufacturing industry the pillar industry of Beibuwan Economical Zone of Guangxi Province. 


\section{References}

[1] National Development and Reform Commission of People's Republic of China. Beibuwan Gulf Economical Zone of Guangxi Development Plan[EB/OL].[2008.2.20]. http://www.sdpc.gov.cn.

[2] li de ming Eastern part of Guangxi, to undertake the transfer of industries in economically developed areas of strategic thinking[J].guihai forum2008,24(2):70-72. (in Chinese)

[3] Guangxi Zhuang Autonomous Region Bureau of Statistics. Guangxi Statistical Yearbook[M].beijing: China Statistics Press,2009. (in Chinese)

[4] wang tian wei. Gulf Economic Zone policy advantages of[J]. Popular Science,2009,(8):196-198. (in Chinese)

[5] guo feng ming. AHP Choice of model[J]. Systems Engineering Theory \& Practice, 1997(9):54-57. (in Chinese) 